\title{
Pattern and determinants of psychogeriatric disorders in old age psychiatric unit, Baghdad, Iraq
}

\author{
Shalan Joodah Rhemah Al Abbudi ${ }^{*}$; Khalida Ibraheem Ezzat ${ }^{2}$ \\ ${ }^{1}$ Department of Medicine, Al-Imamein Al-Kadhimein Medical City, Iraq \\ ${ }^{2}$ Counseling, Social worker, Ibn-Rushd Mental Hospital, Iraq
}

*Corresponding Author(s): Shalan Joodah Rhemah Al Abbudi

Consultant Psychiatrist, Section of Psychiatry, Department of Medicine, Al-Imamein Al-Kadhimein Medical City, Baghdad, Iraq

Email: shalanjoodah@yahoo.com

Received: Aug 21, 2018

Accepted: Nov 12, 2018

Published Online: Nov 15, 2018

Journal: Journal of Psychiatry and Behavioral Sciences

Publisher: MedDocs Publishers LLC

Online edition: http://meddocsonline.org/

Copyright: (C) Al Abbudi SJR (2018). This Article is distributed under the terms of Creative Commons Attribution 4.0 International License

Keywords: Pattern; Determinants; Elderly; Psychiatry; Iraq

Abbreviations: OAPU: Old Age Psychiatry Unit; SAMHSA: Substance and Mental Health Services of America; OCD: Obsessive Compulsive Disorder; CVA: Cerebrovascular Accident

\section{Abstract}

Backgroud: Mental disorders in old age are frequent.

Objectives: To determine the pattern of psychiatric disorders of elderly clients aged $\geq 60$ years, attending the old age psychiatry unit, Ibn-Rushed psychiatric teaching hospital, Baghdad, Iraq.

Methods: A retrospective study to all attendees to the old age psychiatry unit between January, 2009 and November, 2011 was carried out. Data collected included diagnoses, comorbid disorders, treatment received, and socio demographic characteristics.

Results: Analysis of 907 clients done, mean age $68 \pm$ 6.3 years, $67.5 \%$ age range $60-69$ years, $70 \%$ married, $50 \%$ without income (unemployed and housewives), 52\% illiterate, and $98.5 \%$ live with their families. Depression was $46.9 \%$, schizophrenia $23.2 \%$, and $20.7 \%$ dementia. $48 \%$ of clients had comorbid illness. $100 \%$ had at least one pharmacological medication. Diagnoses high statistical significant association with sex $(P=0.000)$, marital status $(P=0.001)$, occupation $(P=0.000)$, and education level $(P=0.000)$.

Conclusion: Mental health of old age needs proper assessment and early detection. Most mental disorders are treatable once detected. This study recognizes the need for the proper integration of mental health into primary health care system of the country and the need to train mental health care providers.

Cite this article: Al Abbudi SJR, Ezzat KI. pattern and determinants of psychogeriatric disorders in old age psychiatric unit, Baghdad, Iraq. J Psychiatry Behav Sci. 2018; 4: 1017. 


\section{Introduction}

Ageing is an inevitable developmental phenomenon bringing along a number of changes in the physical, psychological, hormonal and the social conditions. Define ageing in terms of the biology; referring to "the regular changes that occur in mature genetically representative organism living under reprehensive environmental conditions as they advance in chronological age." old age has been viewed, as problematic period of one's life and this is correct to same extent [1]. Population ageing is a global phenomenon affecting both developed and developing countries with several implications [2]. Ageing is a normal process, which is associated with physical, social and psychological changes. The number of older population of both developed and developing countries has considerably increased in the 20th century [3]. The elderly population is growing faster than the total population throughout the world [4]. Currently, the number of people aged 60 and over is more than 800 million. Projections indicate that this figure will increase to over two billion in 2050. People aged 60 can now expect to survive an additional 18.5 to 21.6 years [5]. The majority of older people live in low- and middle income countries, and some of the fastest rates of ageing are occurring in these areas [6,7]. It is estimated that between $5 \%$ and $17 \%$ of the older adults suffers from a mental disorder, $[8,9]$. Factors such as poverty, social isolation, loss of independence, loneliness and losses of different kinds, can affect mental health and general health. Older adults are more likely to experience events such as bereavements or physical disability that affect emotional well-being and can result in poorer mental health. $[10,11]$. Many researchers have divided old age into three categories; Early old age or young old age which extended from age 60 to age 69 . Old age or advanced old age, this begins at the age 70 and ends at age 79 . From the age 80 and the above is considered older old age. The disintegrating system of joint family, rapid industrialization and urbanization and changing social values have together caused serious problem for the aged. They are treated like an unavoidable burden if they ceased to remain productive members. Occupational problems of aging are generally accepted fact that the lack of employment security of older [1]. Many older people with a mental disorder also have a comorbid or co-existing physical illness or disability. Specialist geriatric psychiatry services include assessment, treatment, rehabilitation and clinical liaison services provided by one or more members of a multidisciplinary team. In Iraq, mental health services for older people presented within the old age psychiatry unit (OAPU), Ibn-Rushed psychiatric teaching hospital, Baghdad. Old Age Psychiatry Unit (OAPU) was established at December, 2008. Interdisciplinary team was trained in geriatric psychiatry services at Michigan, USA, through Iraq-SAMHSA initiative, first cohort (June - July) 2008.

Aim: The aim of this study was to determine the pattern of psychiatric disorders seen in elderly patients aged 60 years and above attending the Old Age Psychiatry Unit (OAPU), Ibn-Rushed psychiatric teaching hospital, Baghdad, Iraq, and to determine and explore factors that affected their management,

\section{Patients and methods}

Design and setting: This is a retrospective study with analytic component. It was conducted in the Old Age Psychiatry Unit (OAPU), Ibn-Rushed psychiatric teaching hospital, Baghdad, Iraq. The data collection was done during the period January, 1st, 2009 to November, 1st, 2011. Ibn-Rushed psychiatric teach- ing hospital was one of the major mental hospitals in Iraq, with adult and child outpatient psychiatric clinic, deal with acute cases, with about 70 beds for short stay inpatients, serving all Iraqis. Record system of the hospital was renewed after year 2005; paper file system and appointment card system were founded. Electronic record computerized system was established during 2009-2010. Old age psychiatry unit have its own separated records. All paper files were converted into computerized system. Appointment card system was updated. Study Population and Sampling: all elderly clients aged 60 years and above attending at the Old Age Psychiatry Unit (OAPU) regularly both sexes were included. Sample Size: sample size was determined by the total number of clients visited the Old Age Psychiatry Unit (OAPU) during January, 2009-November, 2011. Inclusion criteria: All elderly aged $\geq 60$ years, of both sexes, have regular visits, and with complete record. Exclusion criteria all clients with incomplete data were excluded from the study. Data collection Tools: Information extracted from the case notes file system were entered into information list. The information included sociodemographic variables, main clinical features at presentation, diagnoses, co-morbid physical disorders, type of treatment given to the patients. Definition of variables: The independent variables were socio-demographics, age, gender, marital status, level of education, occupation, admission times, and comorbid condition. Statistical Analysis: Data extracted were analyzed using SPSS 17 software for windows. Ethical Issues: Names were kept anonymous and all paper files and electronic records were kept with full privacy.

\section{Results}

Demographic data: The total number of patients referred to the hospital during the 3 years was 4534 . Clients age 60 and above, visited the old age psychiatry unit, were 931 . Only 24 clients had incomplete record were excluded from the study. Clients had complete records with regular visits and follow up were 907 ( 493 male and 414 female), and this accounted for about $20 \%$ of the total referral for the three years under study. Their mean age was $68 \pm 6.3$ years. Majority of the clients (67.5\%) were within the age range $60-69$ years. about $70 \%$ were married. Clients without income (unemployed and housewives) were about $50 \%$. Clients had no formal education were $52 \%$. About $98.5 \%$ live with their families (Table 1 ).

Diagnoses: Depression, schizophrenia, and Dementia were the three most common diagnoses, $46.9 \%, 23.2 \%$, and $20.7 \%$ respectively. Conditions such as generalized anxiety disorders, substance abuse, Parkinsonism, bipolar disorder, obsessive compulsive disorder, and epilepsy accounted for another $9.3 \%$ (Table 2).

Nature of co-morbid physical illness: Forty eight percent of the clients had co-morbid physical illnesses. Hypertension, diabetes mellitus, and GIT disease accounted for about $55 \%$ of comorbidity (Table 3).

Mode of Treatment: All (100\%) of the clients received pharmacotherapy as the main treatment. Majority, $64.1 \%$, was with two drugs medication (Table 4).

Significance: A cross classification of clients with 9 different diagnosis by socio-demographic explored high statistical significant association with sex $(P=0.000)$, marital status $(P=0.001)$, occupation ( $P=0.000)$, and education level $(P=0.000)$ (Table 5). 
Table 1: Distribution of the study group by sociodemographic characteristics and smoking habit

\begin{tabular}{|c|c|c|c|c|c|c|c|}
\hline & & \multicolumn{4}{|c|}{ Sex } & \multicolumn{2}{|c|}{ Total } \\
\hline & & \multicolumn{2}{|c|}{ Male } & \multicolumn{2}{|c|}{ Female } & \multirow[t]{2}{*}{ No } & \multirow[t]{2}{*}{$\%$} \\
\hline & & No & $\%$ & No & $\%$ & & \\
\hline \multirow{4}{*}{ Age Group } & 60 yrs-69 yrs & 367 & 59.97 & 245 & 40.03 & 612 & 67.5 \\
\hline & 70 yrs-79 yrs & 100 & 40.82 & 145 & 59.18 & 245 & 27.01 \\
\hline & 80 yrs- 89 yrs & 24 & 54.54 & 20 & 45.46 & 44 & 4.85 \\
\hline & 90 yrs-99 yrs & 2 & 33.33 & 4 & 66.67 & 6 & 0.66 \\
\hline \multirow{4}{*}{$\begin{array}{l}\text { Marital } \\
\text { Status }\end{array}$} & Single & 21 & 50 & 21 & 50 & 42 & 4.6 \\
\hline & Married & 414 & 65.1 & 222 & 34.9 & 636 & 70.12 \\
\hline & Widowed & 45 & 22.73 & 153 & 77.27 & 198 & 21.8 \\
\hline & Divorced & 13 & 41.94 & 18 & 58.06 & 31 & 3.4 \\
\hline \multirow{5}{*}{ Occupation } & Unemployed & 108 & 82.44 & 23 & 17.56 & 131 & 14.4 \\
\hline & Employed & 47 & 73.43 & 17 & 26.57 & 64 & 7.05 \\
\hline & Retired & 280 & 85.89 & 46 & 14.11 & 326 & 35.9 \\
\hline & house-wife & 3 & 0.93 & 323 & 99.07 & 326 & 35.9 \\
\hline & free works & 55 & 91.67 & 5 & 8.33 & 60 & 6.6 \\
\hline \multirow{6}{*}{$\begin{array}{c}\text { Education } \\
\text { Level }\end{array}$} & Illiterate & 169 & 35.89 & 302 & 64.11 & 471 & 52.0 \\
\hline & Primary & 80 & 59.25 & 55 & 40.75 & 135 & 14.8 \\
\hline & Intermediate & 57 & 82.6 & 12 & 17.4 & 69 & 7.6 \\
\hline & Secondary & 104 & 88.13 & 14 & 11.87 & 118 & 13.0 \\
\hline & Institute \& college & 77 & 71.97 & 30 & 28.03 & 107 & 11.8 \\
\hline & postgraduate & 6 & 85.7 & 1 & 14.3 & 7 & 0.8 \\
\hline \multirow{3}{*}{$\begin{array}{l}\text { Living Cir- } \\
\text { cumstances }\end{array}$} & Live With Family & 486 & 54.4 & 407 & 45.6 & 893 & 98.5 \\
\hline & Live Alone & 6 & 85.7 & 1 & 14.3 & 7 & 0.77 \\
\hline & Live In Geriatric House & 1 & 14.3 & 6 & 85.7 & 7 & 0.77 \\
\hline & Total & 493 & 54.4 & 414 & 45.6 & 907 & 100 \\
\hline
\end{tabular}

Table 2: Frequency and percentage of medical diagnoses among the study group.

\begin{tabular}{|l|c|c|}
\hline \multicolumn{1}{|c|}{ Diagnosis } & Frequency & $\%$ \\
\hline Dementia & 188 & 20.7 \\
\hline Depression & 425 & 46.9 \\
\hline Schizophrenia & 210 & 23.2 \\
\hline Anxiety & 22 & 2.4 \\
\hline substance abuse & 15 & 1.7 \\
\hline Parkinsonism & 28 & 3.1 \\
\hline Bipolar disorder & 9 & 1.0 \\
\hline OCD & 2 & 0.2 \\
\hline Epilepsy & 8 & 0.9 \\
\hline Total & 907 & 100.0 \\
\hline
\end{tabular}

OCD for obsessive compulsive disorder
Table 3: Frequency and percentage of comorbidity among the study group.

\begin{tabular}{|l|c|c|}
\hline \multicolumn{1}{|c|}{ Comorbidity } & Frequency & $\%$ \\
\hline Respiratory & 5 & 0.6 \\
\hline Vision & 8 & 0.9 \\
\hline Hearing & 13 & 1.4 \\
\hline Renal system & 36 & 4.0 \\
\hline GIT & 97 & 10.7 \\
\hline CVA & 26 & 2.9 \\
\hline Hypertension & 242 & 26.7 \\
\hline Diabetes Mellitus & 152 & 16.8 \\
\hline Ischemic Heart Disease & 30 & 3.3 \\
\hline Hyperlipidemia & 5 & 0.6 \\
\hline Rheumatology & 15 & 1.7 \\
\hline No Comorbidity & 465 & 51.3 \\
\hline
\end{tabular}

GIT for gastrointestinal tract disorders, CVA for cerebrovascular accidents, 
Table 4: Frequency and percentage of drug medication

\begin{tabular}{|l|c|c|}
\hline & Frequency & $\%$ \\
\hline One Drug Medication & 69 & 7.6 \\
\hline Two Drug Medication & 581 & 64.1 \\
\hline Three Drug Medication & 253 & 27.9 \\
\hline Four Drug Medication & 4 & 0.4 \\
\hline Total & 907 & 100.0 \\
\hline
\end{tabular}

Table 5: Distribution of the study group by medical diagnoses and the socio-demographic characteristics

\begin{tabular}{|c|c|c|c|c|c|c|c|c|c|c|c|c|c|}
\hline & & \multicolumn{9}{|c|}{ Diagnosis } & \multicolumn{2}{|c|}{ Total } & \multirow[t]{2}{*}{$P$} \\
\hline & & 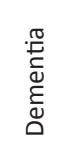 & 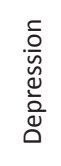 & 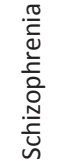 & $\begin{array}{l}\vec{d} \\
\frac{\vec{d}}{x} \\
\frac{c}{4}\end{array}$ & 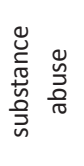 & 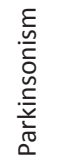 & $\begin{array}{l}\frac{1}{0} \\
\frac{0}{0}\end{array}$ & ૫ે & 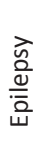 & No. & $\%$ & \\
\hline \multirow{4}{*}{ Age Group } & $60 y r s-69 y r s$ & 129 & 264 & 158 & 14 & 11 & 20 & 9 & 1 & 6 & 612 & 67.5 & \\
\hline & 70yrs-79yrs & 53 & 129 & 43 & 8 & 3 & 6 & 0 & 1 & 2 & 245 & 27. & \\
\hline & $80 y r s-89 y r s$ & 6 & 27 & 8 & 0 & 1 & 2 & 0 & 0 & 0 & 44 & 4.9 & \\
\hline & $90 y r s-99 y r s$ & 0 & 5 & 1 & 0 & 0 & 0 & 0 & 0 & 0 & 6 & 0.6 & \\
\hline \multirow{2}{*}{ Sex } & Male & 115 & 218 & 98 & 17 & 15 & 21 & 5 & 1 & 3 & 493 & 54.4 & 0.000 \\
\hline & Female & 73 & 207 & 112 & 5 & 0 & 7 & 4 & 1 & 5 & 414 & 45.6 & \\
\hline \multirow{5}{*}{ Occupation } & Unemployed & 38 & 52 & 25 & 1 & 2 & 12 & 1 & 0 & 0 & 131 & 14.5 & \\
\hline & Employed & 6 & 36 & 20 & 1 & 0 & 0 & 0 & 0 & 1 & 64 & 7.1 & \\
\hline & Retired & 90 & 137 & 62 & 15 & 5 & 9 & 5 & 1 & 2 & 326 & 35.9 & \\
\hline & house-wife & 51 & 166 & 90 & 4 & 0 & 6 & 3 & 1 & 5 & 326 & 35.9 & \\
\hline & free works & 3 & 34 & 13 & 1 & 8 & 1 & 0 & 0 & 0 & 60 & 6.6 & \\
\hline \multirow{4}{*}{ Marital Status } & Single & 4 & 15 & 17 & 0 & 1 & 3 & 0 & 0 & 2 & 42 & 4.6 & \\
\hline & Married & 138 & 292 & 137 & 21 & 13 & 22 & 6 & 2 & 5 & 636 & 70.2 & \\
\hline & Widowed & 45 & 104 & 40 & 1 & 1 & 3 & 3 & 0 & 1 & 198 & 21.8 & \\
\hline & Divorced & 1 & 14 & 16 & 0 & 0 & 0 & 0 & 0 & 0 & 31 & 3.4 & \\
\hline \multirow{6}{*}{ Education } & Illiterate & 78 & 248 & 103 & 7 & 6 & 18 & 3 & 2 & 6 & 471 & 52.0 & \\
\hline & Primary & 22 & 71 & 30 & 2 & 1 & 7 & 1 & 0 & 1 & 135 & 14.8 & \\
\hline & Intermediate & 15 & 31 & 16 & 4 & 1 & 1 & 1 & 0 & 0 & 69 & 7.6 & \\
\hline & Secondary & 61 & 24 & 25 & 1 & 6 & 1 & 0 & 0 & 0 & 118 & 13.0 & \\
\hline & Institute \& college & 12 & 45 & 35 & 8 & 1 & 1 & 4 & 0 & 1 & 107 & 11.8 & \\
\hline & Postgraduate & 0 & 6 & 1 & 0 & 0 & 0 & 0 & 0 & 0 & 7 & 0.8 & \\
\hline \multicolumn{2}{|c|}{ Total } & 188 & 425 & 210 & 22 & 15 & 28 & 9 & 2 & 8 & 907 & 100.0 & \\
\hline
\end{tabular}

\section{Discussion}

Old age psychiatry unit attendees accounted for about $20 \%$ of the total referral of the hospital. This number appears small and may not represent the true mental health status of the older population. Some of the possible reasons suggested for the reluctance of older adults to seek and continue with mental health care include physical frailty, transportation difficulties, isolation, stigma, and patient provider preferences. Current violent atmosphere, feeling unsecured, and terror car and belts explosions were affecting the total number of attendees.
There is therefore the need for the proper integration of mental health into the primary health care system of this country and the training of mental health care providers at that level of care to identify, provide basic intervention measures and refer when necessary, elderly patients with mental health problems to the tertiary level of health care system. If this is done access to mental health care will be increased for the elderly patients in the community. This study sample is higher number of attendees than the studies carried out in different country $[12,13,14,15]$, 
and lower than American study (2010), Two thousand three hundred seventy five residents aged 60 and older living in non institutional settings. Data are from the National Institutes of Mental Health Collaborative Psychiatric Epidemiological Studies [16]. Current study showed that depression (46.9\%), schizophrenia (23.2\%), and Dementia (20.7\%), similar to study done in Accra, Ghana (1997) that found depression (51.4\%) higher than dementia (31.5\%) [12]. Other studies showed dementia more frequent than other diagnosis $[13,17]$. from these studies, dementia is becoming more common than it was once thought in this environment. Current study found dementia less frequent than depression and schizophrenia which is less than expected. Possible explanations for the small number would include a lower cut off age of 60 years used as the inclusion criteria in this study which could have increased the number of clients with other diagnoses to be included in the study. This is lower than the cut off age of 65 years used in previous studies. Advances in medicine are permitting many people to live to the age of sixty or more, with the result that the proportion of the world community over the age of 60 years is rapidly increasing [18]. Thus the practice in the past as reported by Prince [19], where less attention was given to dementia because it was considered to be a relatively uncommon condition. Depressive syndromes are frequent in old age $[20,21]$ and especially frequent are minor forms of depression like dysthymia, or subsyndromal depression. Although late-life depression is a chronic and disabling illness, there is a common misconception that it is a normal feature of aging. Depression at old age is therefore under-recognized and severely under-treated, especially in very old age with high somatic comorbidity [22]. Poor physical health has long been recognized to be one of the most important risk factors for depression in older adults. Beside comorbid organic syndromes, personal history of depression, death of spouse, health related factors and anxiety disorders show significant associations with incidence of depression [23]. Chronic organic mental disorders, dementias, are the main reason for the necessity of geriatric care units. Dementia is defined as a syndrome of acquired impairment of memory and other cognitive functions secondary to structural brain damage. The clinical interface of depression and dementia is a rich and complex topic [24]. Depressive disorders often cause cognitive symptoms [25]. The term depressive pseudo dementia is used to describe substantial but reversible cognitive impairment caused by an episode of major depression $[26,27]$. Old depressive patients who complain about cognitive disturbances are at particular risk of being labeled as demented $[24,28,29,30]$. Generalized Anxiety Disorder possibly a pre-stage of depressive illness in many old patients, is very frequently found in medical institutions. In The Longitudinal Aging Study Amsterdam [31], which was based on a random sample of 3107 older adults, the overall prevalence of anxiety disorders was estimated at $10.2 \%$. Generalized anxiety disorder was the most common disorder (7.3\%), followed by phobic disorders (3.1\%), whereas panic disorder (1.0\%) and obsessive compulsive disorder $(0.6 \%)$ were rare. Vulnerability factors such as female sex, lower education level, traumatic experiences, stresses commonly experienced by older adults (recent losses of family members and chronic somatic illness), and a smaller size of the social network appeared to be associated with anxiety disorders. Current study founded statistical significant association of old age attendees diagnoses and presence of walking aids like wheel chairs or walking sticks $(P=0.000)$, that explored getting disability as going older. Stephan et al (2014) founded disability was associated with advancement in age [2]. In conclusion, old age is a growing category with some bio psychosocial privacy.
Mental disorders in old age are frequent. Mental health of old age needs proper assessment and early detection. Many old age people were with limited access to mental health services due to physical frailty, transportation difficulties, isolation, stigma, and patient provider preferences. Mental health services must be designed to meet the needs of older people at all points of the mental health continuum. This study recognizes the need for the proper integration of mental health into primary health care system of the country and the need to train mental health care providers at that level of care to identify and provide basic intervention measures and refer when necessary, to the tertiary level of care. Mental health promotion should be embedded in all policies, programs, and services for all older adults (including those with mental illness) and their caregivers, and encompass anti stigma strategies, public awareness, education, and training. Older adults, caregivers, service providers and the public should be informed about the importance of early identification of symptoms of mental illness, prevention strategies and the hope for recovery and well-being. Transformation of a mental health service system must include training, education and support for caregivers and health care providers to increase their capacity to respond to the mental health needs of seniors.

\section{Limitations}

Hospital based sample give good clue but cannot generalized the results. Limited access to unit, prevent many client continued regular visits.

\section{Acknowledgement}

We greatly appreciate the patients and medical staff of the Ibn Rushed hospital for their participation and assistance with this research study.

\section{Statement of ethics}

Names were kept anonymous and all paper files and electronic records were kept in secured system with full privacy.

\section{Author Contribution}

Shalan Joodah Rhemah Al Abbudi, Consultant Psychiatrist, data collection, data entry, electronic record system, data analysis, and the writer of this paper. Khalida Ibraheem Ezzat, Social worker, data collection, data entry, and file record system.

\section{References}

1. Dhara RD, Jogsan YA. Depression and Psychological Well-being in Old Age. J Psychol Psychother. 2013; 3: 117.

2. Stephen O, Wandera, James Ntozi, Betty Kwagala. Prevalence and correlates of disability among older Ugandans: evidence from the Uganda National Household Survey. Global Health Action. 2014; 7: 1-9.

3. Ranjan. et al. Prevalence of depression in elderly people. Health Renaissance. 2013; 11: 213-218.

4. Sanjay TV, Jahnavi R, Gangaboraiah B, Lakshmi P, Jayanthi S. International Journal of Health \& Allied Sciences. 2014; 3: 105109.

5. UNFPA, The State of World Population 2012

6. WHO. Are you ready? What you need to know about ageing. WHO. 2012.

7. WHO. Functional decline and dependence in ageing populations, panel side event at 66th World Health Assembly. 2013. 
8. Ritchie K, Artero S, Beluche I, Ancelin ML, Mann A, Dupuy AM, et al. Prevalence of DSMIV psychiatric disorder in the French elderly population. Br J Psychiatry. 2004; 184: 147-152.

9. Trollor JN, Anderson TM, Sachdev PS, Brodaty H, Andrews G. Prevalence of mental disorders in the elderly: the Australian National Mental Health and Well-Being Survey. Am J Geriatr Psychiatry. 2007; 15: 455-466.

10. Pinquart $M$, Duberstein PR. Treatment of anxiety disorders in older adults: a meta-analytic comparison of behavioral and pharmacological interventions. Am J Geriatr Psychiatry. 2007; 15: 639-651.

11. Veerbeek MA, Oude Voshaar RC, Pot AM. Effectiveness and predictors of outcome in routine out-patient mental health care for older adults. Int Psychogeriatr. 2014; 26: 1565-1574.

12. Turkson SNA, Asamah V. Common psychiatric disorders among the elderly attending a general psychiatric outpatient clinic in Accra, Ghana: a five year retrospective study (i989-1993). West Afr J Med. 1997; 16: 146-149.

13. Mafullul YM, Ikwuagwu PU. Psychiatric disorders of old age in Jos, Nigeria. Nig Med Pract .1996; 31: 29-31.

14. Uwakwe R. Psychiatric morbidity in elderly patients admitted to non- psychiatric wards in a General Teaching hospital in Nigeria. Int J Geriat Psychiatry. 2000; 15: 346-354.

15. Uwakwe R. The pattern of psychiatric disorders among the aged in a selected community in Nigeria. Int J Geriat Psychiatry. 2000; 15: 355-362.

16. Jimenez D E, Alegrıa M, Chen CN, Chan D, Laderman M. Psychiatric Illness in Older Ethnic Minority Adults. J Am Geriatr Soc. 2010; 58: 256-264.

17. Baiyewu O, Adeyemi JD, Ogunniyi A. Psychiatric disorders in $\mathrm{Ni}-$ gerian nursing home residents. Int J Geriat Psychiatry. 1997; 12: 114650.

18. Waterson E. The care of the elderly in Zimbabwe. Central Afr J Med. 1982; 28: 278.

19. Prince $M$. The need for research on dementia in developing countries. Tropical Medicine and International Health. 2000; 2: 993-1000.

20. Snowdon J. The prevalence of depression in old age. Int J Geriatr Psychiatry. 1990; 5: 141-144.
21. Cole MG, Bellavance F, Mansour A. Prognosis and depression in elderly community and primary care populations: a systematic review and metaanalysis. Am J Psychiatry. 1999; 156: 11821189.

22. Mulsant BH, Ganguli M. Epidemiology and diagnosis of depression in late life. J Clin Psychiatry. 1999; 60: 9-15.

23. Schoevers RA, Beekman AT, Deeg DJ, Geerlings MI, Jonker C, Van Tilburg W. Risk factors for depression in later life; results of a prospective community based study (AMSTEL). J Affect Disord. 2000; 59: 127-137.

24. Raskind MA. The clinical interface of depression and dementia. J Clin Psychiatry. 1998; 59: 9-12.

25. Burt D, Zembar M, Niederehe G. Depression and memory impairment: a meta-analysis of the association, its pattern, and specifity. Psychol Bull. 1995; 117: 285-305.

26. Fischer P. The spectrum of depressive pseudo-dementia. J Neural Transm. 1996; 47: 193-203.

27. Emery VO, Oxman TE. Update on the dementia spectrum of depression. Am J Psychiatry. 1992; 149: 305-317.

28. Fischer P, Simany M, Danielczyk W. Depression in dementia of the Alzheimer type and in multi-infarct dementia. Am J Psychiatry. 1990; 147: 1484.

29. Berger AK, Fratiglioni L, Forsell Y, Winblad B, Bäckman L. The occurrence of depressive symptoms in the preclinical phase of $A D$. Neurology. 1999; 53: 1998-2002.

30. Zubenko GS. Neurobiology of major depression in Alzheimer's disease. Int Psychogeriatr. 2000; 12: 217-230.

31. Beekman AT, Bremmer MA, Deeg DJ, van Balkom AJ, et al. Anxiety disorders in later life: a report from the Longitudinal Aging Study Amsterdam. Int J Geriatr Psychiatry. 1998; 13: 717-726. 